\begin{tabular}{|l|l|l|l|l|l|l|}
\hline InterteXto & Uberaba & UFTM & $\begin{array}{l}\text { v. 3 } \\
\text { n. } 2\end{array}$ & p. 25-34 & 2010 - jul. / dez. & ISSN 1981-0601 \\
\hline
\end{tabular}

\title{
A LÓGICA SIMBÓLICA E A REPRESENTAÇÃO DA PERSONAGEM EM “O EMBONDEIRO QUE SONHAVA PÁSSAROS”, DE MIA COUTO
}

\author{
THE SYMBOLIC LOGIC AND THE REPRESENTATION OF \\ CHARACTER IN THE MIA'S COUTO STORY "THE BIRD-DREAMING \\ BAOBAB"
}

\begin{abstract}
Jaqueline Chassot $^{1}$
Resumo: Este trabalho busca analisar elementos da lógica do mito, bem como aspectos da representação da personagem no conto "O embondeiro que sonhava pássaros", de Cada homem é uma raça (1998), de Mia Couto. Para isso, observam-se elementos da trama que apontam para uma lógica mítica, através de contribuições de dois estudiosos do mito: Eleazar M. Mielietinski (1987) e Zelita Seabra (1996). Também se observam traços que indicam a valorização da lógica racional do ocidente, os quais resultam da tentativa de desvalorização cultural do protagonista, o passarinheiro cego. O menino branco, Tiago, encantado pelo universo maravilhoso desvendado pelo passarinheiro, estabelece a ligação com o sagrado, a qual acontece quer através dos pássaros, quer através do embondeiro, ou através do fogo, uma mutação por entre os reinos da natureza, que se fundem e difundem.
\end{abstract}

Palavras-chave: Lógica; Mito; Representação.

Abstract: This work searches to analyze the logic elements of myth, as well as aspects of the representation of character in the story "The bird-dreaming baobab", Mia Couto's Every man is a race (1998). For this, there are plot elements that point to a mythic logic, through contributions of two scholars of myth: Eleazar M. Mielietinski (1987) and Zelita Seabra (1996). Also were observed traces that indicate the value of rational logic of the West, which result from the attempt of cultural devaluation of the protagonist, the bird blind. The white boy, Tiago, enchanted by the wonderful universe unveiled by the bird, connects to the sacred, which happens either by birds, or through the baobab, or through fire, a mutation among the kingdoms of nature, which merge and diffuse.

Key-words: Logic; Myth; Representation.

"O embondeiro que sonhava pássaros" é um dos contos do livro Cada homem é uma raça (1998), do escritor moçambicano Mia Couto. Esse conto tem por tema o choque resultante da incompreensão cultural na sociedade colonial portuguesa. A personagem principal é um vendedor de pássaros,

\footnotetext{
${ }^{1}$ Secretária Executiva do Campus Cerro Largo da Universidade Federal da Fronteira Sul. jaqchassot@yahoo.com.br
} 


\begin{tabular}{|l|l|l|l|l|l|l|}
\hline InterteXto & Uberaba & UFTM & $\begin{array}{l}\text { v. 3 } \\
\text { n. 2 }\end{array}$ & p. 25-34 & 2010 - jul. / dez. & ISSN 1981-0601 \\
\hline
\end{tabular}

negro, desprezado e finalmente massacrado pelos brancos habitantes da vila colonial.

O passarinheiro mora no oco de uma árvore, o embondeiro. Passa todas as manhãs pelos bairros dos colonos brancos vendendo seus pássaros e tocando gaita-de-boca. Com isso, ele introduz a desordem no cotidiano dos moradores adultos, provocando, ao mesmo tempo, a hostilidade dos adultos e a fascinação das crianças pelos "pássaros tão encantantes". Os pais não querem que seus filhos se aproximem do passarinheiro e, por isso, induzemnos à desconfiança no negro, destituído do direito de pisar com seus pés descalços o chão da terra onde nasceu. Certo dia, começam a acontecer coisas estranhas nas casas dos colonos, "Portas e janelas se abriam sozinhas, móveis apareciam revirados, gavetas trocadas." (p.66) 2. Irritados, os brancos decidem acabar de vez com a interferência do negro sobre seu mundo domesticado, organizado.

Dentre as crianças, quem mais se aproxima do vendedor de pássaros é o menino Tiago, "criança sonhadeira, sem outra habilidade senão perseguir fantasias" (p. 64). Decididos os colonos pela eliminação do passarinheiro, Tiago corre a avisá-lo do que se prepara. Apesar de alertado pelo menino, o passarinheiro não foge. É ele o verdadeiro filho dessa terra. Por isso veste-se de cerimônia para receber "os visitantes. Lhe competia respeito, deveres de anfitrião" (p. 68). Espancado pelo bando armado, é conduzido à prisão. Mas, misteriosamente, após ser torturado, ele desaparece. Tiago procura-o no embondeiro, mas o passarinheiro não está lá. O menino, então, recolhe-se no oco do tronco e põe-se a tocar a gaita e a sonhar. Os colonos também saem à procura do desaparecido. Ao chegarem ao embondeiro, ouvem o som da gaitade-boca e acreditam que o passarinheiro lá se encontra. Então ateiam fogo à árvore.

Um aspecto que sobressai no conto é a representação da personagem 


\begin{tabular}{|l|l|l|l|l|l|l|}
\hline InterteXto & Uberaba & UFTM & $\begin{array}{l}\text { v. 3 } \\
\text { n. 2 }\end{array}$ & p. 25-34 & 2010 - jul. / dez. & ISSN 1981-0601 \\
\hline
\end{tabular}

principal, o passarinheiro. Ele é apresentado pelo narrador sempre como o excluído pelos colonos. Já na abertura do conto, percebe-se o menosprezo de que essa personagem é vítima:

Esse homem sempre vai ficar de sombra: nenhuma memória
será bastante para lhe salvar do escuro. Em verdade, seu astro
não era o Sol. Nem seu país não era a vida. Talvez, por razão
disso, ele habitasse com cautela de um estranho. O vendedor
de pássaros não tinha sequer o abrigo de um nome.
Chamavam-lhe o passarinheiro. (p. 63 )

No fragmento, a não-vinculação do passarinheiro à ordem dominante pode ser observada por meio dos aspectos relacionados à personagem, os quais se opõem diametralmente aos que caracterizam essa ordem. Ao estar associado à esfera do noturno, marcada pelos termos "sombra" e "escuro", e, conseqüentemente, ao âmbito do que é estranho à "vida", o passarinheiro contrasta com a ordem vigente, que é a ordem da claridade e das coisas vivas.

Ao longo do conto, muitas outras nomeações the são atribuídas, provenientes da fala dos colonos: "preto" (p. 64), "pés descalços" (p. 64), "negro" (p. 64, 65 e 66), "tipo" (p.65), "sacana" (p.66), "gajo" (p.69) e "velho" (p.69). Esses termos marcam a não-pertença do passarinheiro à vida social da vila colonial, bem como o estranhamento causado pela relação dessa personagem com uma ordem não-natural, conforme observamos pelos fragmentos a seguir:

Por detrás das cortinas, os colonos reprovavam aqueles abusos. Ensinavam suspeitas aos seus pequenos filhos aquele preto quem era? Alguém conhecia recomendações dele? Quem autorizava aqueles pés descalços a sujarem o bairro? Não, não, e não. O negro que voltasse ao seu devido lugar. Contudo, os pássaros tão encantantes que são insistiam os meninos. Os pais se agravavam: estava dito" ( $p$ 64).

No primeiro fragmento, observa-se a dualidade de sentimentos em

\footnotetext{
${ }^{2}$ Todas as referências ao conto de Mia Couto serão retiradas da edição citada, registrando-se, somente, o número de página.
} 


\begin{tabular}{|l|l|l|l|l|l|l|}
\hline InterteXto & Uberaba & UFTM & $\begin{array}{l}\text { v. 3 } \\
\text { n. 2 }\end{array}$ & p. 25-34 & 2010 - jul. / dez. & ISSN 1981-0601 \\
\hline
\end{tabular}

relação ao passarinheiro. Ao mesmo tempo em que o narrador apresenta, através do discurso indireto livre, a reprovação dos moradores acerca da liberdade de o passarinheiro circular pelas ruas do bairro, fortemente destacada pela reiteração "Não, não, e não"; ele também mostra o encantamento causado pela presença do passarinheiro e seus pássaros na vida das crianças da comunidade. Esse contraste de opiniões está marcado, no texto, pela palavra "contudo", e aponta para duas diferentes perspectivas: a perspectiva pragmática e racional dos colonos; e a perspectiva não-pragmática da sedução da beleza e do sonho representada pelo passarinheiro.

(2)Os senhores receavam as suas próprias suspeições - teria aquele negro direito a ingressar num mundo onde eles careciam de acesso? Mas logo se aprontavam a diminuir-lhe os méritos: o tipo dormia nas árvores, em plena passarada. Eles se igualam aos bichos silvestres, se concluíam. (p. 65).

(3)Aquela música se estranhava nos moradores, mostrando que aquele bairro não pertencia àquela terra. Afinal, os pássaros desautenticavam os residentes, estrangeirando-lhes? Ou culpado seria aquele negro, sacana, que se arrogava a existir, ignorante dos seus deveres de raça? O comerciante devia saber que seus passos descalços não cabiam naquelas ruas"(p. 66).

No segundo e no terceiro fragmentos, há a manifestação do medo dos moradores em relação ao poder de sedução do passarinheiro. Na tentativa de subjugar essa sedução, os colonos buscam rebaixar a personagem, seja igualando-a aos bichos, seja desfazendo de sua música. Manifesta-se, nessas passagens, a diferença entre as duas visões do mundo, bem como o medo diante do desconhecido, uma vez que os colonos percebem que o negro tem acesso a um tipo de realidade que Ihes é vedado, o mundo mágico, encantado da natureza. Temem os moradores que o acesso do passarinheiro a essa outra ordem os faça perder sua identidade; provoque a retomada, pelo mundo natural, do território subjugado pelos brancos. Para acabar com a causa do seu medo, o último recurso que os colonos empregam é a violência, conforme se 


\begin{tabular}{|l|l|l|l|l|l|l|}
\hline InterteXto & Uberaba & UFTM & $\begin{array}{l}\text { v. 3 } \\
\text { n. 2 }\end{array}$ & p. 25-34 & 2010 - jul. / dez. & ISSN 1981-0601 \\
\hline
\end{tabular}

observa no quarto fragmento:

(4)Interroguem o gajo, espremam-no bem. Era ordem dos colonos, antes de se retirarem. O guarda continenciou-se, obediente. Mas nem sabia que segredos devia arrancar do velho (p.69).

Nesse fragmento, observa-se 0 argumento da violência, recurso definitivo na eliminação da presença inconveniente do passarinheiro no bairro colonial. O uso da violência representa a dificuldade em aceitar o que não se entende; nesse caso, elimina-se o que é perturbador, mesmo sem saber as razões da condenação.

O procedimento de exclusão que os colonos brancos manifestam em presença do passarinheiro reproduz a cultura racional da sociedade ocidental que busca eliminar tudo o que não se conforma a seus padrões. Assim, incomoda aos colonos a maneira de viver do passarinheiro, que não tem as mesmas preocupações dos moradores. O passarinheiro tem a liberdade de tocar sua gaita, de morar no oco de uma árvore, de conviver com os pássaros, de sonhar, de admirar e sentir a beleza da natureza, de se maravilhar perante os mistérios do mundo sem procurar dar a eles uma explicação racional. Para ele, mais importante que a funcionalidade dos elementos da natureza, é a sua beleza e perfeição. O passarinheiro carrega consigo a inocência das crianças e, por isso, conquista a amizade dos filhos dos moradores.

A liberdade do passarinheiro, suas atitudes, seu acesso a essa realidade mágica da natureza e o mundo não-racional que ele simboliza causam medo aos colonos portugueses. Aumenta ainda mais o estranhamento o fato de 0 passarinheiro ser um nativo. Com a circulação do vendedor ambulante pelas ruas da vila, os moradores receiam perder o espaço conquistado $\mathrm{e}$ domesticado. Essa realidade do mundo natural ameaça-os pela sua força de sedução. Então, para se defender dessa situação adversa, para subjugar o que não compreendem, os colonos buscam eliminar, através da violência, a ameaça representada pelo vendedor de pássaros. 


\begin{tabular}{|l|l|l|l|l|l|l|}
\hline InterteXto & Uberaba & UFTM & $\begin{array}{l}\text { v. 3 } \\
\text { n. } 2\end{array}$ & p. 25-34 & 2010 - jul. / dez. & ISSN 1981-0601 \\
\hline
\end{tabular}

As ações são apresentadas por um narrador não-personagem, em terceira pessoa onisciente, que está fora da história, mas que observa de perto a situação. Na terminologia de Tzvetan TODOROV (As categorias da análise literária), um narrador heterodiegético, com visão por detrás.

Um outro aspecto relevante, nesse conto, é o desenvolvimento de duas lógicas culturais antagônicas: por um lado, a lógica racional, dominante na cultura ocidental, própria dos colonizadores portugueses; e, de outro lado, a lógica do mito, apresentada na figura do passarinheiro. E o menino? Ah! O menino, como toda a criança, está ainda na fase anímica, mágica. Ainda não foi "domesticado" por essa outra visão. Por isso é que ele percebe que as flores do embondeiro se tingem do sangue do negro. Também por isso é que ele ouve as histórias, e acredita nelas.

Acolhido no interior do embondeiro, é lá que Tiago sonha que se transforma em árvore

seus cabelos se figuravam pequenitas folhas, pernas e braços se madeiravam, os dedos, lenhosos, minhocavam a terra. $O$ menino transitava de reino: arvorejado, em estado de consentida impossibilidade. (p.70-71)

A passagem citada marca a transição realizada por Tiago, no sonho, de um mundo terreno e humano ao mundo natural. Essa transição se completa ao final do conto, no qual o menino passa inteiramente para a ordem do mito: "sentiu a ferida das labaredas, a sedução da cinza.(...) aprendiz de seiva, se emigrou inteiro para suas recentes raízes" (p. 71).

Observemos, então, como se identificam essas duas lógicas distintas.

Em seu texto introdutório à lógica do mito, A poética do mito (1987), o teórico russo Eleazar Mielietinski chama atenção para o fato de a lógica do mito ter penetrado nas literaturas do "terceiro mundo", incluindo a africana, a partir dos anos 50-60, ou seja, numa época de marcada racionalização e dominada pela máquina. A cultura dos povos ocidentais modificou-se muito no após a II Guerra Mundial. A constatação do fracasso da cultura racional do ocidente, 


\begin{tabular}{|l|l|l|l|l|l|l|}
\hline InterteXto & Uberaba & UFTM & $\begin{array}{l}\text { v. 3 } \\
\text { n. 2 }\end{array}$ & p. 25-34 & 2010 - jul. / dez. & ISSN 1981-0601 \\
\hline
\end{tabular}

exposto pela sucessão de duas guerras de extensão nunca vista, possibilitou a tentativa de pensar a realidade de maneira mais integrada, facilitando a aceitação de um pensamento que permitisse a coexistência e a interpenetração de elementos de historicismo e mitologismo, realismo social e folclore autêntico (MIELIETINSKI, 1987, p. 433). Observa-se, a partir de então, o desenvolvimento de uma literatura de curta extensão, com grande revalorização dos elementos simbólicos, em especial nos contos.

No conto de Mia Couto, os elementos de lógica simbólica (lógica do mito) se manifestam através da introdução do elemento maravilhoso no corpo da narrativa, ao lado da norma racional. Ele está presente, por exemplo, na representação do embondeiro, que é a árvore em cujo oco mora o passarinheiro. O conto apresenta a crença africana de que esta é uma árvore santa, plantada de cabeça para baixo por Deus, e que pega fogo por si mesma. Ou seja, o embondeiro não seria uma simples árvore, elemento vegetal. Seria um elemento provido de alma, com capacidade de sentir e também agir. Tratase de uma lenda de animização da natureza, o que também se verifica com a flor do embondeiro.

- Está a ver a flor? - perguntou o velho.

E lembrou a lenda. Aquela flor era moradia dos espíritos. Quem fizesse mal ao embondeiro seria perseguido até o fim da vida. (p. 68)

Nesse fragmento, observa-se o poder humano da natureza, possível somente através da lógica simbólica presente no conto. A animização da natureza manifesta-se nessa lenda por meio da reação das flores do embondeiro, que seria a morada dos espíritos, frente às maldades feitas à árvore.

Além disso, no conto, as folhas do embondeiro caem quando a árvore fica triste ao ver o passarinheiro ser levado preso: "Então, foi então: as flores do embondeiro tombaram, pareciam astros de feltro. No chão, suas brancas pétalas, uma a uma, se avermelharam.” (p. 69). É a reação da natureza 


\begin{tabular}{|l|l|l|l|l|l|l|}
\hline InterteXto & Uberaba & UFTM & $\begin{array}{l}\text { v. 3 } \\
\text { n. 2 }\end{array}$ & p. 25-34 & 2010 - jul. / dez. & ISSN 1981-0601 \\
\hline
\end{tabular}

animizada perante a atitude humana.

A estudiosa Zelita Seabra, em seu livro Tempo de Camélia - O espaço do mito (1996), apresenta a relação da animização da natureza com a lógica afetiva do pensamento mítico. Na lógica afetiva, as perguntas que nos conduzem às causas de um evento são: "Quem?", "Quem quis?", "Quem mandou?" Os fatos são causados por emoções - ódio, amor, ciúme, e revelam uma vontade.

A lógica afetiva difere do pensamento racional. Segundo Seabra, cabem ao pensamento racional as perguntas "Como?" e "Por quê?" e suas resposta. Leis gerais regem o comportamento individual e social, assim como explicam movimentos históricos. Conceitos e princípios universais - gravidade, inércia, densidade, evaporação e condensação - organizam o mundo dos fenômenos.

Dessa forma, os elementos da natureza, no conto, fogem ao pensamento racional, uma vez que a natureza não é apresentada como inanimada e não interessa saber os "comos" e os "porquês". Conforme Seabra (1996), trata-se de um mundo que é um "tu" - thou, e os animais, plantas ou seres brutos aparecem como um mundo vivo. (SEABRA, 1996, p. 33) Esse thou é diferente do $I t$, que é mais racional. O thou é próprio do pensamento mítico.

Para a estudiosa, toda experiência do "thou" é altamente individual; e o homem primitivo encara os acontecimentos como eventos individuais. Tais eventos e suas explicações só podem ser concebidos como uma ação que necessariamente toma a forma de uma história.

Ainda segundo Seabra, no mito, nenhum evento é "natural", a morte menos que qualquer outro. Já que o mundo fenomênico é um "thou" que o confronta, o homem primitivo pergunta-se pela vontade intencional que comete um ato. O primitivo pergunta: "Por que deveria este homem morrer assim, neste momento?" A lógica da racionalidade apenas pode dizer que, em determinadas condições, a morte sempre ocorrerá. Para o pensamento mítico, deve ser encontrada uma causa tão individual e específica quanto o evento que 


\begin{tabular}{|l|l|l|l|l|l|l|}
\hline InterteXto & Uberaba & UFTM & $\begin{array}{l}\text { v. 3 } \\
\text { n. 2 }\end{array}$ & p. 25-34 & 2010 - jul. / dez. & ISSN 1981-0601 \\
\hline
\end{tabular}

deve explicar. O evento não é analisado intelectualmente; é experienciado em sua complexidade e sua individualidade... A morte é "querida", intencionada. A questão, então, vira-se mais uma vez do "por quê?" para o "quem?".

A narrativa de Mia Couto apresenta o mistério envolvendo as ocorrências estranhas e inexplicáveis que acontecem, as quais têm como alvo o universo social e burocrático do bairro branco: aos Silvas, foi aberto o "móvel das armas"; apareceu "alpista na gaveta dos documento" dos Peixotos; "Os sérios requerimentos municipais cheios de caganitas" em casa do presidente do município (p. 67).

Não haver explicação lógica para estas ocorrências, leva-nos a subentender que tratar-se-iam de manifestações sobrenaturais e que, os habitantes, possivelmente, também assim o pensavam, como podemos ver na frase "O qual, ninguém, nenhum, nada" (p.67).

Outro elemento mítico/fantástico/misterioso é o desaparecimento do passarinheiro da prisão:

Acordou num chilreino. Os pássaros! Mais de infinitos, cobriam toda a esquadra. Nem o mundo, em seu universal tamanho, era suficiente poleiro. Tiago se acercou da cela, vigiou o calabouço. As portas estavam abertas, a prisão deserta. $\mathrm{O}$ vendedor não deixara nem rastro, o lugar restava amnésico. Gritou pelo velho, responderam os pássaros (p.70).

Nesse fragmento, o mistério do desaparecimento do passarinheiro intensifica-se com o também misterioso surgimento de um bando de pássaros. Essa situação também só pode ser compreendida pelo menino Tiago, que tem o poder de compreender os mistérios do mundo não-racional.

A partir da observação desses dois aspectos que se destacam na narrativa curta de Mia Couto, a saber, a representação do passarinheiro e os elementos da lógica do mito, pode-se fazer uma associação da realidade apresentada no conto com a realidade social da colonização européia na África, quando os portugueses defendiam a superioridade de sua raça e de sua cultura. Assim, Tiago apresenta sua ligação ao sagrado, a qual acontece quer 


\begin{tabular}{|l|l|l|l|l|l|l|}
\hline InterteXto & Uberaba & UFTM & $\begin{array}{l}\text { v. 3 } \\
\text { n. 2 }\end{array}$ & p. 25-34 & 2010 - jul. / dez. & ISSN 1981-0601 \\
\hline
\end{tabular}

através dos pássaros - que simbolizam a sua ligação com os céus - quer através do embondeiro - símbolo da sua ligação ao terreno - através do fogo símbolo de transformação e de regeneração face ao sofrimento provocado pelo opressor - uma mutação por entre os reinos da natureza, que se fundem e difundem.

\section{Referências}

COUTO, Mia. Cada homem é uma raça; estórias. Rio de Janeiro: Nova Fronteira, 1998.

MIELIETINSKI, E. M. A poética do mito. Trad. Paulo Bezerra. Rio de Janeiro: Forense Universitária, 1987.

SEABRA, Zelita. Tempo de Camélia: o espaço do mito. Rio de Janeiro: Record, 1996. 